\title{
EDUCATION AND OUTREACH
}

The Bioastronomy Symposium was held in tandem with the 2002 Fulbright Symposium "Science Education in Partnership", reflecting the fact that Bioastronomy is a powerful and compelling path to expose young people to science. One afternoon session was shared between the two Symposia, and the following section contains papers resulting from that special education session.

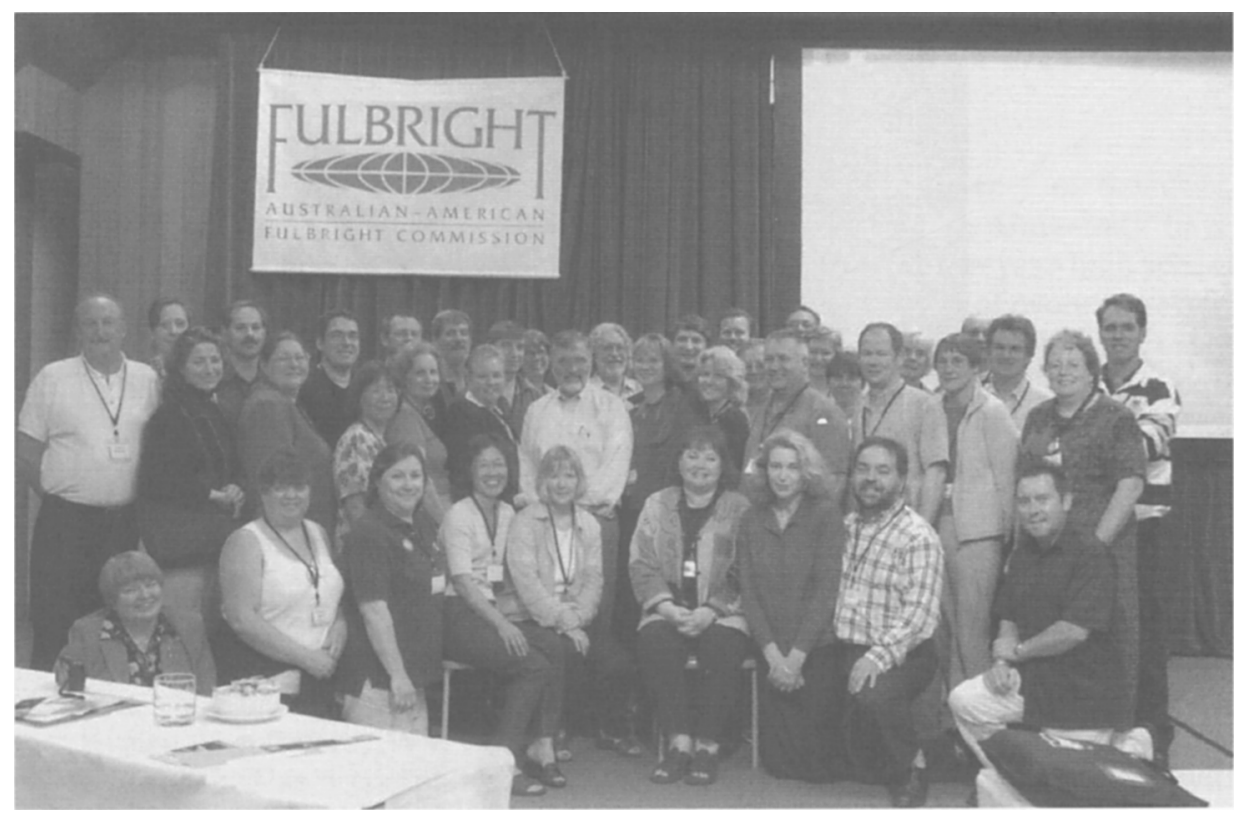

Harrison Schmitt at Fulbright Symposium (photo: Seth Shostak) 


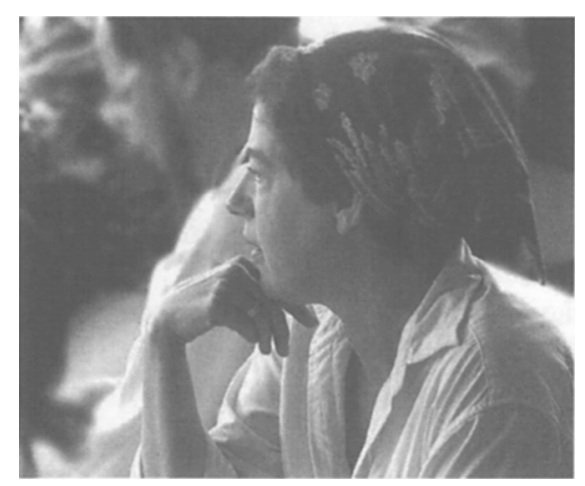

Jane Fisher (photo: Daniella Scalise)

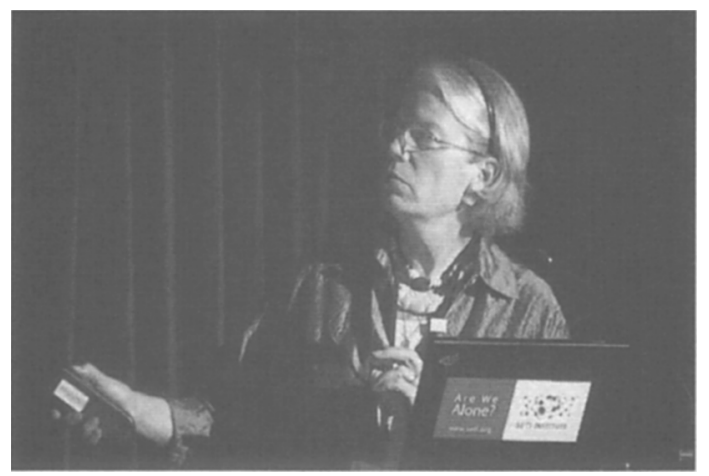

Jill Tarter (photo: Daniella Scalise)

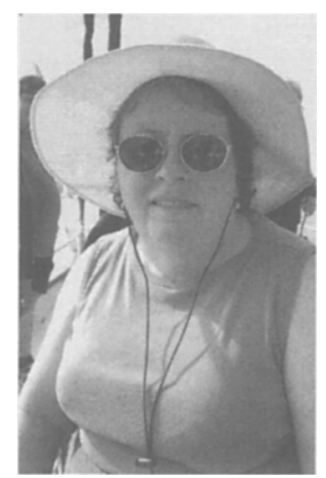

Edna DeVore (photo: Seth Shostak) 


\section{Voyages Through Time: Everything Evolves}

Jane Fisher, Jill Tarter \& Edna DeVore

SETI Institute, 2035 Landings Drive, Mountain View, CA 94043, U.S.A.

Yvonne Pendleton

NASA Ames Research Center, Moffett Field, CA 94035, U.S.A.

Kathleen O'Sullivan

San Francisco State University, 1600 Holloway Avenue, San Francisco, CA 94132, U.S.A.

Meg Burke

California Academy of Sciences, Golden Gate Park, San Francisco, CA 94118, U.S.A.

Abstract. The SETI Institute, the California Academy of Sciences, NASA Ames Research Center, and San Francisco State University have developed standards-based curriculum materials for a one-year high school integrated science course centered on the unifying theme of evolution. Scientists, teachers, curriculum writers, and media specialists are currently finalizing six modules that integrate astronomical, geological, and biological sciences as well as the history of science and technology. The sequence of lessons in each module is designed to promote students' understanding and skills as defined by the National Science Education Standards and Benchmarks for Science Literacy. The modules cover: Cosmic Evolution, Planetary Evolution, Origin of Life, Evolution of Life, Hominid Evolution, and the Evolution of Technology. The core lessons for all six modules are provided via CD-ROM, including instructional guidelines, science background information, and additional resources (print, audiovisual, software, WWW sites, and databases). These products will be published as a complete set for use as a yearlong science course and will also be available as individual modules for use in discipline-based courses. Evolutionary change is a powerful framework for studying our world and our place therein. It is a story of epic size, capable of inspiring awe and of expanding our sense of time and place. This story is the basis of Voyages Through Time. 


\section{Introduction}

Evolutionary change underpins much scientific theory and thought: the origin of the universe and life cycle of stars, the formation of the Earth and its oceans and continents, the origin and diversification of life, the emergence of Homo sapiens, and the development of scientific knowledge and technology. Curriculum materials constructed around this exciting and extraordinarily fruitful concept will offer students a connected, scientific view of today's world as a dynamic system, the result of on-going processes that began billions of years ago and continue today, as well as an historical perspective of how scientific knowledge changes by evolving over time, almost always building on earlier knowledge.

\section{The Project}

The SETI Institute, the California Academy of Sciences, NASA Ames Research Center and San Francisco State University are working together to produce a standards-based curriculum for a high school science course centered on the unifying theme of evolution, titled Voyages Through Time (VTT). The scope and potential of evolution as a theme for science curricula is widely acknowledged. In addition to the biological and geological facets of evolution, The National Science Education Standards (National Research Council 1996) and The Benchmarks for Science Literacy (American Association for the Advancement of Science 1993) both identify evolution as a major conceptual theme which extends beyond these disciplines. In the National Science Teachers Association's The Core Content (1992) evolution is recommended as an overarching theme for an integrated high school science course. The study of evolution also requires attention to concepts of scale for size and time, complex interactions between systems (e.g., life's alteration of the Earth's atmosphere), the relationship between evidence and theory, what is known with some certainty and what remains unknown, and the interplay among science, technology, and society in developing scientific understanding. Scientists, educators, curriculum writers, and media specialists have developed six modules that integrate astronomical, geological, and biological science as well as the history of science and technology. Each module requires five to six weeks of instruction. Taken together, the six modules comprise a yearlong integrated science course. A summary of the module content follows:

- Cosmic Evolution treats theories about the origin of the universe and the light elements $(\mathrm{H}, \mathrm{He})$, the gravitational collapse of first stars, the production of heavier elements, the development of second-generation stars and planetary systems like our own, and the historical events that displaced the Earth from the center of the universe and developed the ideas of a galaxy-filled cosmos.

- Planetary Evolution investigates the long history of the changing surface and atmosphere of Earth by comparing it with Venus and Mars, their internal structures, plate tectonics and impacts, the interactions of energy, matter and life that shape the Earth, the concept of habitable planets, and the historical development of the theories of geological time and plate tectonics. 
- Origin of Life focuses on the sources of energy and early organization of matter, carbon as a key element for life, the formation and structure of the building blocks of more complex molecules, the evolution of single-celled life including the 3 billion years during which all life was microscopic and the continuing dominance of single-celled life, and the original discoveries about microscopic life as well as more recent ones.

- Evolution of Life treats quantitative as well as qualitative variation, biotic potential, natural selection and other mechanisms of biological evolution, adaptation, extinction and speciation, lines of evidence for biological evolution, heritable and non-heritable characteristics, chance and contingency, the diversity of life and environments over time, and the historical development of the theory of biological evolution.

- Hominid Evolution addresses the fossil evidence for hominid evolution and the range of scientific interpretations thereof, humans' molecular kinship with extant species, the relationships among hominid characteristics in evolution (e.g., bipedalism, brain size), humans' unique constellation of cognitive and developmental characteristics, the development of the earliest technologies, and human impacts on other species and the environment.

- Evolution of Technology focuses on the development of and changes in Homo Sapiens sapiens' technologies (e.g., agriculture, manufacturing, medicine, sanitation, transportation, information processing and communications), the differences between science and technology, and the relationships among science, technology, and society.

The instructional framework for VTT is based upon the constructivist model from the Biological Sciences Curriculum Study-BSCS (ed. Bybee 1996). This instructional strategy guides students to develop scientific skills and understandings and to deal with their misconceptions. Briefly, the BSCS instructional sequence - the 5 Es-may be summarized as:

- Engage: Activities engage students' interest in the topic, identify current understandings and misconceptions, and pose questions to be addressed in the module.

- Explore: Activities provide first-hand experiences with phenomena that develop the concepts, processes, and skills targeted in the module; students keep written records of data, graphs, text, and sketches.

- Explain: Activities consolidate the prior lessons through student presentations and discussions; the teachers provide additional explanations and formal terms; students read articles and documents.

- Elaborate: Activities have students apply and extend ideas and skills to new examples and information; timelines of key events are constructed; students manipulate "real data" provided on CD-ROMs.

- Evaluate: Ongoing assessments of learning are embedded throughout the module and student self-assessment is promoted. Both performance and traditional assessments are provided for summative evaluation. 
From the teacher's perspective, the materials incorporate sound instructional practices. They provide detailed instructions for their use and guide teachers unfamiliar with the 5E's pedagogy to incorporate new ways of taking account of student ideas, engaging students with phenomena, developing and using scientific ideas, promoting student reflection, assessing progress, and enhancing the learning environment.

VTT will be published as an electronic, rather than print, curriculum on CD-ROMs for several reasons. The United States National Education Technology Plan's goals for technology in education are that "all teachers and students will have access to information technology; all teachers will use technology effectively to help students achieve high academic standards; all students will have technology and information literacy skills; research and evaluation will improve the next generation of technology applications; and digital content and networked applications will transform teaching and learning." These goals recognize that just providing schools with increasingly sophisticated technology is insufficient: teachers need well-articulated and standards-based curricula and the ability to make full and appropriate use of the technologies. The VTT CDROM provides teachers full interactive support: science background articles, planning calendars, the Standards and Benchmarks addressed by each module, student misconceptions and difficulties to be anticipated, glossary, safety considerations, consolidated materials lists, lessons with printable student materials, evaluation tools (tests), and media-still images, demonstration videoclips, simulations, models, and databases. Although many lessons are traditional laboratory activities appropriate for the science classroom, students also use the computer to analyze scientific databases, e.g., to compare the various characteristics of stars to derive the temperature-luminosity relationship. The curriculum also provides many short videoclips of a diversity of scientists discussing their research. Students learn from the videoclips that science is dynamic, that scientists don't always agree, and that much of the content of the VTT modules are areas of active and ongoing scientific research. But students also need to read about scientists and scientific discovery. For each module, there is a student reader of articles drawn from popular science magazines, e.g., Sky and Telescope, Earth, and Discover. Students learn current science through lively writing and are exposed to interesting publications that they may continue to read as adults. When published, VTT will be supported by a dedicated web site with up-to-date web references, a teachers' chat room, FAQs, and support.

\section{Development Process and Current Status}

VTT is a 4.5 year project that began in the summer of 1998 with a month-long workshop where teachers, scientists, writers and project staff worked together to develop the initial draft of materials and activities. During academic year (AY) 1998-1999, the writers, staff and principal investigators modified and elaborated the workshop products with ongoing reviews by scientific and educational advisors. In AY 1999-2000 and 2000-2001, teachers and students pilot tested the modules in high schools around the greater San Francisco Bay region. During the summer and fall of 2001, the modules were revised based upon the feedback from the regional pilot test. An extensive national field test was conducted dur- 
ing AY 2001-2002 with diverse groups of students and teachers from sixty-six schools in twenty-eight states across the nation. Independent evaluation is being provided by Tania Madfes (WestEd, San Francisco, CA), and Joe McInerney (Foundation for Genetic Education and Counseling, Baltimore, MD, formerly at BSCS, Boulder, CO). Following revisions, based on feedback from the national field testing, VTT will be commercially published in 2003.

\section{Project Participants}

VTT is the product of many people's ideas and labor. In addition to the principal investigators, scientists, teachers, staff and an active advisory committee are contributing to the project.

- Principal Investigators: Jill Tarter, SETI Institute; Yvonne Pendleton, NASA Ames Research Center; Edna DeVore, SETI Institute; Kathleen O'Sullivan, San Francisco State University; Meg Burke, California Academy of Sciences

- Scientists: California Academy of Sciences: Carol Tang, Peter Fritsch, Michael Ghiselin, Nina Jablonski, David Kavanaugh, Gary Williams

- NASA Ames Research Center: David Blake, Sherwood Chang, David Des Marais, Linda Jahnke, Chris McKay, Lynn Rothschild,

- San Francisco State University: Carmen Domingo, Lisa White

- SETI Institute: Max Bernstein, Jason Dworkin, Harold P. Klein, Cynthia Phillips

- 1998 Summer Workshop Teachers: Merle Boxill, San Jose; Daniel Burns, Los Gatos; John Colombero, Campbell; Randall Depew, Concord; Juan Fernandex-Maculet, Campbell; Pamela Harman, Pacifica; Charles Jordann, Los Altos; John Keller, U. of Colorado, Boulder; Ellen Koivisto, San Francisco; Joe Mahood, San Mateo; Gretchen Walker, Union City; Aimee Yermish, Hillsborough

- Staff: Jane Fisher, Project Director; Coral Clark, Carolyn Csongradi, Pamela Harman, Noel Johnson, Noah Wittman,Writers; Cara Stoneburner, Curriculum Manager; Marita Beard, Field Test Manager

- Advisory Committee: Jean Beard, San Jose State University; James Burke, London, UK; Michael Carr, US Geological Survey; Frank Drake, SETI Institute; Gordon Freedman, California State University-Monterey Bay; Gene Gallock, EastSide Union High School District; Robert Havlen, Astronomical Society of the Pacific; David Morrison, NASA Ames Research Center; David Milne, Evergreen State College; Norman Pace, University of Colorado; Kevin Padian, UC Berkeley; Eugenie Scott, National Science Education Center; Seth Shostak, SETI Institute; Cary Sneider, Boston Museum of Science; David Thornburg, San Carlos, CA; Vivian Lee Ward, Access Excellence, National Museum of Health; Adrienne Zihlman, UC Santa Cruz. 
- Multi Media Contractor: Learning in Motion, Santa Cruz, Marge Cappo, President.

\section{Project Funding}

VTT is funded by the National Science Foundation, Grant Number ESI-9730693, with additional support from, the Foundation for Microbiology, the HewlettPackard Company, NASA Astrobiology Institute, NASA Fundamental Biology Program, and the many people who contributed to "Educate America" through the Combined Federated Charities campaign.

\section{References}

American Association for the Advancement of Science 1993, Benchmarks for Science Literacy, (New York: Oxford University Press)

Bybee, R. W. 1996, National Standards and the Science Curriculum: Challenges, Opportunities and Recommendations, (Dubuque: Kendall/Hunt)

Jamison, M. A., \& Lewis, P. R. 1997, Getting Ready for Information Space: A Primer on Schools, Feds and Funds, (Schoolwire: http://www.shoolwire.org/primer.html)

National Research Council 1996, National Science Education Standards, (Washington, DC: National Academy Press)

National Science Teachers Association 1992, The Core Content, (Washington, DC: National Science Teachers Association) 